LITERATURA 



\section{AL ALBA DE LA RENOVACIÓN: NOTACIÓN TEMPORAL E INDAGACIÓN CÓSMICA EN LA POESÍA COSTARRICENSE. AZOFEIFA, DEBRAVO, AMIGHETTI Y CHEN SHAM}

Jorge Chen Sham

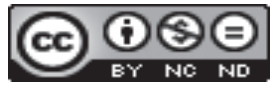

Doi: https://doi.org/10.15517/rfl.v46iExt..43482

URL: https://revistas.ucr.ac.cr/index.php/filyling/index 



\title{
AL ALBA DE LA RENOVACIÓN: NOTACIÓN TEMPORAL E INDAGACIÓN CÓSMICA EN LA POESÍA COSTARRICENSE. AZOFEIFA, DEBRAVO, AMIGHETTI Y CHEN SHAM
}

\author{
AT THE DAWN OF RENEWAL: TEMPORARY NOTATION AND \\ COSMIC INQUIRY IN COSTA RICAN POETRY. AZOFEIFA, \\ DEBRAVO, AMIGHETTI AND CHEN SHAM
}

\author{
Jorge Chen Sham
}

\begin{abstract}
RESUMEN
Este artículo, que teje relaciones y dialoga con el que publica Isaac Felipe Azofeifa en el número 2 de la Revista de Filología y Lingüística de la Universidad de Costa Rica (1975), retoma una de las explicaciones en la autolectura de su escritura, ofrecida por el propio poeta. De esta manera, con la intención de trazar una línea interpretativa, se aborda el tópico del alba en una serie de poetas costarricenses (Azofeifa, Debravo, Amighetti y Chen Sham), en cuyos poemas la mañana se establece como punto de partida de una reflexión y de una celebración que involucra también al yo poético. La dimensión metafísica o existencial cobra todo su sentido a partir de las palabras de Azofeifa, para que desarrolle una retórica del movimiento y de la expansión, tal y como él proponía. La idea del homenaje-réplica a aquel artículo implica al mismo tiempo ofrecer una "autoexplicación" a mi trabajo como poeta, porque él la realizó allí con su poesía; razón por la cual me inserto en una temática y, siguiendo los pasos de Azofeifa, también me desdoblo de mi papel de creador. Palabras clave: tópico del alba; poesía costarricense; Isaac Felipe Azofeifa; Jorge Debravo; Francisco Amighetti y Jorge Chen Sham.
\end{abstract}

\begin{abstract}
This article, which weaves relationships and dialogues with the one published by Isaac Felipe Azofeifa in number 2 of the Revista de Filología y Lingüística de la Universidad de Costa Rica (1975), resumes one of the explanations in the self-reading of his writing, offered by the poet himself. In this way, with the purpose of drawing an interpretive line, the topic of dawn is addressed in a series of Costa Rican poets (Azofeifa, Debravo, Amighetti and Chen Sham), in whose poems the morning is established as the starting point of a reflection and a celebration that also involves the poetic self. The metaphysical or existential dimension takes all its meaning from the words of Azofeifa, to develop a rhetoric of movement and expansion, just as he proposed. The idea of the homage-reply to that article implies at the same time offering a "self-explanation" to my work as a poet, because he carried it out there with his poetry; reason for which I insert myself in a theme and, following in the footsteps of Azofeifa's, I also unfold my role as creator.

Keywords: topic of dawn; Costa Rican poetry; Isaac Felipe Azofeifa; Jorge Debravo; Francisco Amighetti y Jorge Chen Sham.
\end{abstract}

Dr. Jorge Chen Sham. Profesor de la Escuela de Filología, Lingüística y Literatura. Universidad de Costa Rica. San José, Costa Rica. Miembro correspondiente de la Academia Nicaragüense de la Lengua y la Academia Norteamericana de la Lengua Española.

Correo electrónico: jorgechsh@yahoo.com 
A la hora de hablar de su propia obra poética en 1975, Isaac Felipe Azofeifa (19091997), justifica de entrada su propuesta en dos asertos teóricos que es bueno recordar. El primero constituye un principio de la pluralidad del texto y de semiosis interpretativa en el que una lectura nunca puede agotar el texto; aquí Azofeifa sigue a Roland Barthes en su seminal Crítica y verdad, cuando afirmaba que el texto incita siempre a hablar una "segunda lengua" (1966, p. 52), la del lector, la del crítico. Por esa razón, Barthes debilita o erosionaba la "autoridad" del autor y el principio autoris, para plantear la pluralidad de la lectura literaria y, con ello, la primacía del acto creador en tanto evento y máquina performativa que pone a funcionar la connotación de las palabras y los códigos culturales. Ello supone plantear el segundo aserto ofrecido, pues Azofeifa reconoce retomando la tesis de la autorreferencialidad de la comunicación poética, "que la persona que habla en el poema no coincide con el yo empírico del poeta" (1975, p. 3). Aquí sigue a Carlos Bousoño en su Teoría de la expresión poética (1976), con el fin de explorar cómo la expresividad poética funciona para crear una persona (una voz o una máscara que actúa y cobra existencia en el acto de comunicación). Distinguir esta capacidad del lenguaje poético de modelar y de crear otra realidad desemboca en Azofeifa, en la justificación pertinente para emprender esta empresa, siempre difícil por los criterios de valoración y a veces mal comprendida de hablar y de escribir sobre sí mismo. Sin embargo, a Azofeifa se le ha olvidado un tercer aserto (y que yo propongo aquí para justificar el hecho de que él acometa una visión de su propia escritura), el cual también vendría a apoyar su artículo y es que él representa una clase muy especial de poetas, aquellos que son profesores-críticos y pertenecen al ámbito de la academia universitaria ${ }^{1}$. El ejemplo más conspicuo de esta categoría la representan poetas como Jorge Guillén o Pedro Salinas, pertenecientes a la Generación poética del 27 español, los cuales integraron crítica y creación en su biografía personal e intelectual, y en el caso costarricense, el propio Azofeifa, Carlos Rafael Duverrán o Carlos Francisco Monge, Carlos Villalobos, entre otros.

Todo lo anterior permite ahora adentrarse en la autoexplicación que el mismo Azofeifa propone, cuando aborda un primer asedio a su poesía e indica con esa valoración que la distancia y la reflexión previas presuponen: "Leyéndome con esa actitud exploradora que he dicho, acabo de descubrir algo que sólo atino a definir como un sentido matinal de la existencia en mi idea de la vida" (1975, pp. 5-6). En Azofeifa se pone énfasis y se ponderan las transiciones del día a la noche; el movimiento temporal, es decir, la mañana (el alba o la madrugada), la tarde (el crepúsculo) o la noche (el nocturno) se convertirán en el tiempo ideal para llevar a cabo estas transformaciones que conllevan el cambio y su percepción. El tiempo poético, para interpretar este estado de conciencia intensificada o de funcionamiento reflexivo y meditativo, aquilata la mañana, la tarde y la noche, respectivamente, y conducirá al límite de una confrontación en donde se puede trazar el movimiento continuo por las horas del día y, de rebote, obliga a su correlación con la existencia y el tiempo biológico y humano (la infancia, la adultez, la vejez).

De esta manera, a través de la mirada de un yo poético observador, se toma conciencia de la existencia como si fuera un theatrum mundi que le devuelve el espejo de las vicisitudes y de la fragilidad del ser humano, por ejemplo. Este despliegue de la observación / mirada no es nada inocente, está condicionada por la percepción de los cambios del día y del clima

1 Por lo demás, justifica con razón el hecho de que, por solicitud expresa de la Dirección de la Revista, se me haya pedido un trabajo en esta línea interpretativa y con estos presupuestos teórico-metodológicos. 
particulares, que movimientos como el simbolismo finisecular o el impresionismo pictórico matizan y privilegian, para que la mañana, la tarde o la noche se coloreen de una íntima percepción personal. Lo anterior suscita una radical e insospechada respuesta por parte del poeta costarricense, porque el entorno no lo deja indiferente, mientras los motivos temporales seleccionados para darle contenido temporal a su reflexión poética ubican este "sentido matinal" dentro de una experiencia de apertura y una retórica auroral, positiva y eufórica ${ }^{2}$. Lo anterior se vuelve pertinente, cuando Azofeifa más adelante promueva y se encamine en su artículo hacia la absolutización de la experiencia poética y comenta de la siguiente manera: "La imagen matinal de la existencia se asocia, a mi modo de entenderme, con otro sentimiento que encuentro vivísimo en mis poemas. Es la idea de la existencia como crecimiento, como expansión creciente, no como simple y puro cambio" (1975, p. 6, [las cursivas son nuestras]). Ya la filosofía del Romanticismo pensó estas relaciones del tiempo vivencial y la poesía en términos del poder supremo de la naturaleza y del espíritu en su mediación con la realidad apariencial del mundo y de individuo. De ahí el papel y la función del poeta como el mediador que posibilita trascender la realidad apariencial y acercarnos a un proceso de integración con el cosmos, cuya prerrogativa será su capacidad de revelar y de expresar. Y lo explicaba M. H. Abrams en su fundamental estudio sobre el romanticismo inglés, al presentar esta experiencia de vida / creación como una intensificación de los atributos y cualidades del poeta, los cuales son correlativos al proceso de su crecimiento espiritual frente a la contingencia y la apariencia material:

\begin{abstract}
La profunda experiencia que tiene el poeta del sufrimiento y la mortalidad humanos se traduce sistemáticamente en una relación alterada entre su ojo y su objeto: la escena natural articula y devuelve reflejados los sentimientos rudimentarios que le aporta la percepción del espíritu, de tal manera que el correlato de su nuevo mirar al hombre «con otros ojos» es su nueva percepción de los objetos naturales como inmersos en una luz y una sombra diferentes. (Abrams, 1992, p. 88).
\end{abstract}

Para que se despliegue esta revelación y se mire diferencial y radicalmente al individuo y al cosmos del que parte toda vinculación afectiva y estética, se impone un tiempo preferencial en el que la ensoñación y la imaginación deben ejercitarse; se trata de una confrontación en el sentido de que su interpelación moldea la experiencia vital que el poema así desarrolla. Ese crecimiento espiritual del poeta solo es posible si dejamos esa realidad cotidiana y apariencial para perfeccionarnos en la vida interior, restitutiva y reintegrativa, con nuestra propia individualidad, porque, "para ellos [los románticos], son precisamente el sueño y los demás estados 'subjetivos' los que nos hacen descender en nosotros mismos y encontrar esa parte nuestra que 'es más nosotros mismos' que nuestra misma conciencia” (Béguin, 1993, p. 29). Diálogo e intradiálogo que explora esos grandes fantasmas que interrogan siempre al poeta y que se vuelven en una obsesión de la poesía a partir de la estética romántica. Así, la existencia inquietante y el tiempo insondable, como veremos a continuación, preocupan y, desde el punto de vista de la comunicación lírica, colocan la fuerza ilocucionaria, aquella que trata de actuar sobre la actitud y los comportamientos de los destinatarios / lectores, "respecto al texto y a su contexto comunicativo" (Paz Gago, 1999, p. 62) en el ámbito del ritual y acto estilizado. Y aunque para profundizar en el alba, Azofeifa selecciona el poema acápite de Vigilia en pie de muerte (primera edición de 1961), este crecimiento espiritual y la vivencia

2 El movimiento temporal desemboca en una triple notación, mañana / tarde / noche: su impronta en nuestro imaginario poético se relaciona con la significación del "alba resplandeciente", el "éxtasis crepuscular" o "la meditación nocturna", solamente para establecer una tipología temática. 
del "sentido matinal" se abordan mejor en la sección "Júbilo o la naturaleza" y, en especial, en el poema "Después de un cierto silencio". Se trata de una sección que contrasta con el tema de la lucha y la soledad humanas ante la existencia de las otras secciones del poemario, en la cual se revela el conflicto existencial en su poesía en donde la desazón y la angustia aparecen temáticamente. Monge (1984) indica que las relaciones conflictivas con el cosmos y con el individuo poeta se hacen ostensibles para subrayar "el tema del ser en abandono e indefenso" (p. 39), con tres elementos centrales: "la sensación de vivir a tientas, la soledad humana, y el silencio como metáfora del mundo" (p. 39). Los planteamientos de Carlos Francisco Monge conducen a un enfoque "desesperanzador y pesimista" y él lo contrapone a "la visión tranquila y afirmante del mundo" (p. 39). Por el contrario, el silencio se transforma en una necesidad vital para el poeta en una afirmación vitalista y positiva, tal y como se verá en este poema. En cuanto título temporal, se explicita la actitud del yo poético en relación con su estado emocional; el "silencio", sinécdoque del tiempo transcurrido, se vuelve revelador de la retórica de la apertura, el cual comienza con la "salutación" cósmica:

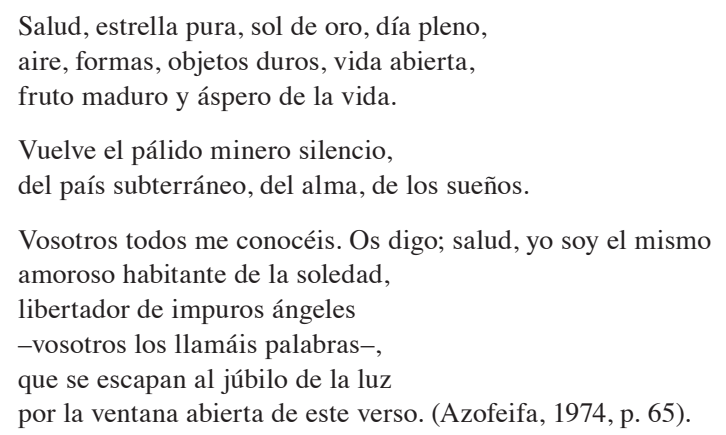

La finalidad perlocutiva de "saludar" involucra una actitud de afabilidad y de cercanía, que aproxima al yo poético en una dimensión de la sacralidad cósmica a la naturaleza y a las cosas en general. Esto es posible en este ascenso de la mirada hacia las alturas que se expanden, porque apela aquí tanto al sol matinal como al universo tangible e intangible dentro de esa enumeración desarrollada entre los versos 2 y 3 . El tiempo del alba es al mismo tiempo el de la integración y el de la colaboración iluminativa, que deja detrás la oscuridad de la noche, de ese "país subterráneo" (v. 5). Involucra una función mágica de la palabra poética, convocada en ese movimiento de "impuros ángeles" (v. 8), los cuales trastocan y empujan al yo poético hacia la expresión sublime (etimológicamente, "sacar desde adentro") de un ritual ante la naturaleza que conmueve al yo poético; aquí se enuncia en el verso 11 en esta imagen benéfica de la mañana: "por la ventana abierta de este verso". Llaman la atención dos cosas: en primer lugar, la utilización del motivo de la "ventana", aquí metaforizada en tanto apertura del poema (y en este sentido está en clave metapoética), se abre como ceremonia vital y estética, hacia el exterior del poeta y del universo (Chen Sham, 2014a, p. 347) ${ }^{3}$; en segundo lugar, se impone el "júbilo de la luz" (v. 10) para que no solamente se desenvuelva obviamente la notación temporal, sino también se expongan los efectos lumínicos que connotan el crecimiento, la expansión y la alegría. No es casual que la oposición luz (día) / oscuridad (noche) permita tanto

3 Más adelante volveremos sobre este motivo. 
el contraste como "por referencia a los efectos sensibles y psicológicos de ambos fenómenos en el ser humano" (Fernández Leborans, 1977, p. 140)" ; así, el "júbilo" expresa esa actitud que conlleva una disposición de apertura y una voluntad de sinergia, que se encuentran en este tipo de poesía calificada de "hímnica". El "himno" es un tipo particular de apóstrofe lírico que designa la vivencia de una experiencia inefable, que el yo poético intenta comprender y expresar; la manifestación de este proceso "se realiza en la excitación de este influjo recíproco" (Kayser, 1981, p. 446) y el destinatario "representa poderes superiores, divinos, a los cuales el yo eleva su canto emocionado" (Kayser, 1981, p. 448), al apelar fuerzas numinosas y la integración con el cosmos, pues "sabe cantar, movido por el deseo de fusión y por su condición de creyente" (Chen Sham, 2007, p. 23). Para no realizar un escorzo que involucre un largo desarrollo, baste mencionar el modelo más conspicuo de la tradición cristiana, como lo es el "Cántico a las criaturas", de San Francisco; cito solamente su comienzo en su versión española:

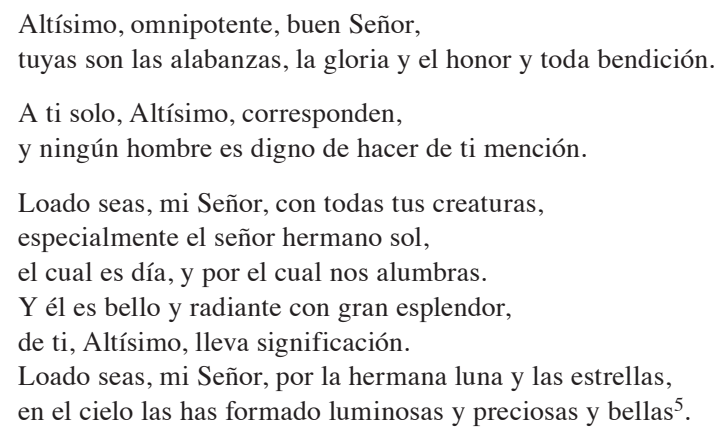

En un contexto de himno a la divinidad, el "Cántico" de San Francisco de Asís guarda todas las partes de los salmos de alabanza del "Antiguo Testamento", a los que se refiriere Marina Mannati: la invocación a la divinidad, la captatio benevolentiae inicial y la alabanza preceden a toda acción de gracias y, en este sentido, cuando se alaba a las criaturas o el portento de la creación permiten enardecer a Dios dentro del tópico de las "maravillas" (Mannati, 1979, p. 21) de la creación. Ahora bien, San Francisco, siguiendo una jerarquía cósmica, comienza con la alabanza a los astros celestes (del Sol a las estrellas); este es el ejemplo seguido por Azofeifa en su "salutación". Ahora bien, el Santo de Asís desarrolla posteriormente en forma descendente con los cuatro elementos primordiales (aire, agua, fuego, tierra) y, con este último, a una evocación de todas las criaturas que habitan el orbe terrestre: "Loado seas, mi Señor, por nuestra hermana la madre tierra, / la cual sustenta y gobierna, / y produce diversos frutos con coloridas flores y hierba" (como se citó en Pozzi, 1976, vv. 20-21).

La serie culmina, en ese orden descendente de la creación divina, con los seres humanos, a los que San Francisco observa a partir del perdón y el sufrimiento. Lo mismo sucede en Azofeifa, continúa con su salutación en una estructura tripartita, que no es nada inocente en su ritmo cabalístico; esta segunda invoca al "cielo azul" y al espectáculo del movimiento de las nubes: "Salud, cercano azul, / nubes de paso por el cielo / como un barco

$4 \quad$ Aunque el título del libro no lo explicite, María Jesús Fernández Leborans desarrolla toda una reflexión sobre esta oposición luz / oscuridad, que ha pasado desapercibida por la crítica literaria.

5 Cito por la traducción que aparece en el artículo "Releyendo el Cántico del hermano sol", de Giovanni Pozzi (1976, vv. 1-11), profesor de literatura italiana en la Universidad Católica de Friburgo, Suiza, en: http://www.franciscanos.org/estudios/pozzi.htm. (consultado el 23 de marzo de 2020). 
fantasma del verano; / montaña familiar / cuyo pie de piedra y lianas / el belfo fresco de los ríos lame / con lengua fiel" (Azofeifa, 1974, vv. 21-27, p. 66).

Como si fuera un cuadro que se pinta pictóricamente con las palabras, surge el cielo azul, las nubes, la montaña y el lecho de los ríos, dentro de un movimiento también descendente. La sensación de cercanía y de afectividad se marcan por el adjetivo "familiar" del verso 24, mientras el dinamismo y el movimiento se inscriben no solamente en las "nubes de paso" del verso 22, sino también en su comparación con el "barco fantasma del verano", cuya travesía es incierta y sin rumbo fijo. Ahora bien, la tercera invocación recubre el elemento "tierra", para que la mirada ahora se ancle con imágenes de lo telúrico en tanto crecimiento vital al irradiar una alegría colectiva: "Salud, cereales núbiles, cañas adolescentes, / finas palmeras jóvenes / (v. 30) -un viento apasionado las posee-. / Salud, anciano cedros / en vuestra propia sombra adormecidos. / Salud, vosotros, corazones próximos, abiertos" (1974, vv. 28-33, p. 66).

Los tres primeros adjetivos, "núbiles", "adolescentes" (v. 28) y "jóvenes" (v. 29), inundan con esa energía propia del bullicio y algarabía; estos contrastan en efecto con la imagen de los "ancianos cedros" (v. 31) en reposo. Sin embargo, forjan esa dinámica inherente al crecimiento y al desarrollo, para que la naturaleza funcione benignamente y en diapasón energética; su influencia se propaga a todo ser viviente, cuando se dirige también el yo poético, a la humanidad, de esos "corazones próximos, abiertos" (v. 33) y pueda concluir, su cántico en una profesión de fe que involucra la integración de su proyecto personal, la del poeta que escribe y pondera sus versos, dentro del universo biográfico, cotidiano y a la vez espiritual:

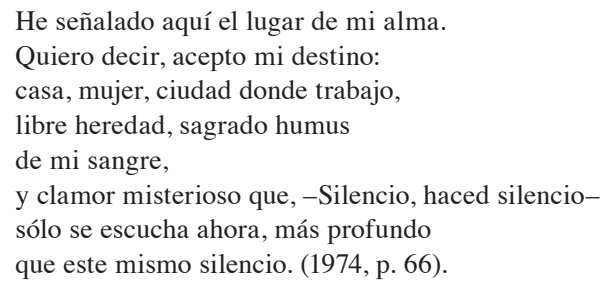

La enumeración, que integra aquí elementos tangibles e intangibles, marca el inicio de la aceptación de un "destino" (v. 35), lo cual desemboca no tanto en la aceptación de sus deberes patrimoniales o en los bienes que deben ser protegidos, como en el compromiso que lo obliga a acrecentarlo para ser fiel a sí mismo. La recapitulación autobiográfica a la que se asiste en este final del poema pondera las cualidades cognoscitivas del poeta en la paradoja: "Silencio, [...] sólo se escucha ahora, más profundo / que este mismo silencio" (vv. 39-41). El par escucha / silencio integra esa capacidad espiritual del que sabe profundizar y auscultar allí en donde solamente el poeta pone su oído y su receptividad, de abrirse a las cosas y al mundo, a la acción y a la construcción de utopías. No nos extrañe, entonces, que Jorge Debravo (19381967) escriba un poema como "La misa buena"; poema que ocupa un lugar preferencial en la estructuración del poemario Nosotros los hombres (1ª edición de 1966, 1979 versión), con ese llamado matinal a la comunión colectiva.

De esta manera, al intensificar esa necesidad de que el poder salvífico se manifieste hic et nunc y transforme las existencias humanas, los actos y las palabras del ritual de la eucaristía católica se convierten en una experiencia que solamente puede entenderse dentro de una fenomenología de la religión, pues se trata de que la comunión y la celebración sean la expresión de la presencia de la divinidad. Así, la búsqueda de una "comunión” de los hombres 
nos arrastra al performance del lenguaje; el sentido jubilatorio y festivo se impone desde el inicio con la voz colectiva que se reúne bajo el "nosotros"; la perífrasis verbal incoactiva se carga de un valor demostrativo, capaz de reunir y convocar a la vez:
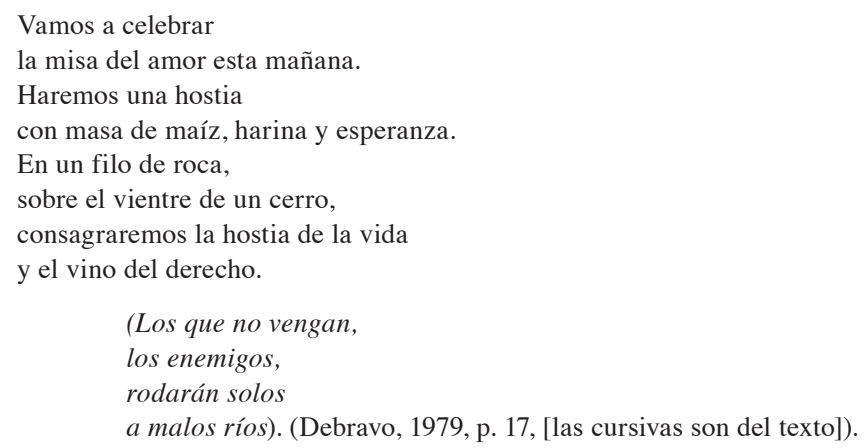

Todo el impulso humano y la dinámica del movimiento se concentran en la perífrasis "Vamos a celebrar", mientras la notación temporal se despliega ("esta mañana") para que el espíritu de renovación y de acción de gracias justifiquen el acto matinal. Pero también las formas verbales en futuro arrastran esa fuerza asertiva y de resolución, cuyo origen es el encuentro y la unión en el amor. Como buen lector de las epístolas del "Nuevo Testamento", Jorge Debravo ha hecho del amor el centro de su edificio ideológico; sobre todo del amor de Dios y la identidad de los cristianos. El texto clave es la "Primera Carta de San Juan":

\begin{abstract}
Queridísimos, amémonos los unos a los otros, porque el amor es de Dios; y el que ama, ha conocido a Dios. El que no ama no ha conocido a Dios, porque Dios es amor. En esto se ha manifestado el amor de Dios por nosotros: en que ha mandado a su Hijo único al mundo, para que nosotros vivamos por él. En esto consiste su amor: no somos nosotros los que hemos amado a Dios, sino Dios el que nos ha amado a nosotros y ha enviado a su Hijo como víctima propiciatoria por nuestros pecados. Queridísimos, si Dios nos ha amado de este modo, también nosotros debemos amarnos los unos a los otros. Jamás ha visto nadie a Dios. Si nos amamos los unos a los otros, Dios mora en nosotros, y su amor en nosotros es perfecto. (1 San Juan, Cap. 4, versículos 7-12, Santa Biblia, 1974, p. 1432).
\end{abstract}

No hemos podido cortar la cita, porque explica el principal fundamento del cristianismo en ese amor profundo e imperecedero del Padre a sus criaturas y cualquier pretensión de amor a Dios desemboca aquí en el mandamiento de amor hacia los hermanos. Según Horacio Lona, quien ha analizado con atención las llamadas cartas apostólicas, lo que define al creyente es su condición de ser hijos de Dios, cuya filiación es primero manifestación de su amor, para que luego se extienda e irradie la fraternidad entre aquellos que se llaman "cristianos" (2003, p. 109). Él concluye de la siguiente manera:

\footnotetext{
El discurso sobre el amor de Dios posee ante todo una dimensión vertical -es Dios el que habla y demuestra su amor al hombre mediante el envío de su Hijo-, pero a ésta le sigue necesariamente una dimensión horizontal que se expresa en el mandato del amor mutuo en la comunidad y en la respuesta que el creyente debe dar a esta exigencia. (Lona, 2003, p. 108).
}

El amor comunitario y su celebración gozosa desembocan en el símbolo de "la misa del amor" (v. 2), en donde el pan y el vino cobran unas resonancias indiscutibles para quien trate de ver: tanto la reunión entre cristianismo y utopía socialista que aglutina su proyecto autorial como una manera particular de analizar la praxis poética de Jorge Debravo: "consagraremos la hostia de la vida / y el vino del derecho" (vv. 7-8). Precisamente, desde este punto de vista, esta fuerza plural embarga todos los sentimientos de colectividad y de pertenencia en el poema de 
Debravo que analizamos. Desembocan en esta eucaristía renovada que, alzando "una hostia / con masa de maíz, harina y esperanza" (vv. 3-4), se nutre y se fermenta bajo una concepción del "amor" fraterno. Y al respecto indican Margarita Rojas y Flora Ovares refiriéndose a Debravo: "La confianza en la transformación del mundo actual lleva a algunos casos a la propuesta de utopías. Para construirlas recurre a imágenes religiosas, que se humanizan" (1995, p. 212).

No es casual, entonces, que en el centro de esta experiencia de fe se halle el sacramento de la eucaristía, pues si la fe nace de la predicación y del testimonio actualizado de quien repite el acto de compartir el pan y el vino. La solución evangélica es clara, al "adaptar el anuncio a las categorías del que oye" (Gelabert, 1990, p. 126) dentro de una mesa compartida. Así, la predicación planteada en el "Sermón de la Montaña" exige para el cristiano que la comunión lo obligue a experimentar la fuerza y el misterio de un acto colectivo. En el contexto evangélico, remite a esa multitud que se reúne en la gran multiplicación del pan en la que participa Jesús. Así, se trata del pan que Jesús comparte y multiplica para saciar el hambre de los hambrientos, como sucede a orillas del Lago de Galilea, por ejemplo, en donde reunió a una gran multitud e hizo sus milagros, pero como los días pasaban y había hambre, hizo lo siguiente en lo que se conoce como la "Segunda multiplicación de los panes":

\begin{abstract}
Mas Jesús llamó a sus discípulos y les dijo: "Me da lástima de la gente, porque llevan conmigo ya tres días y no tienen qué comer. Y no quiero despedirlos ayunos, no sea que desfallezcan en el camino". Los discípulos le dijeron: “De dónde procuraremos en un despoblado panes suficientes para saciar a tantos?”. Jesús les dijo: “¿Cuántos panes tenéis?". Ellos contestaron: "Siete y algunos pececillos". Mandó a la gente a sentarse en tierra. Tomó los siete panes y los peces, dio gracias, los partió y los dio a los discípulos y éstos a la gente. Comieron todos y se saciaron [...]. (San Mateo, Cap. 15, versículos 32-37, Santa Biblia, 1974, p. 1167).
\end{abstract}

Observemos con atención en Debravo la composición heterogénea de dos tipos de harina en esta hostia que congrega y alimenta: por un lado, están presentes tanto el trigo como el maíz en una conjunción inusual para significar el mestizaje latinoamericano; pero por otro, se le agrega un fermento, la "esperanza", cosa inusual en la composición de la hostia, por ser un pan ácimo, sin levadura. Una nueva hostia se consagra, pero tampoco se hace en cualquier lugar. Si retomamos el inicio de la predicación de Jesús es necesario apuntar ahora que el Sermón de la Montaña, episodio del cual forma parte la multiplicación de los panes, se realiza cuando Jesús sube a los altos de un "monte" (San Mateo, Cap. 5, versículo 1, Santa Biblia, 1974, p. 1152), desde el cual se dirige a la multitud que lo ha seguido. En Debravo, la "misa buena" se realiza "sobre el vientre de un cerro" (v. 6), ahí se consagra el pan y el vino renovados en vida y derecho. Luis Maldonado analiza el contexto del festín mesiánico en el "Antiguo Testamento" para subrayar la relación entre comida, su convivio y la plenitud del Reino; se trata de la realización del "ágape escatológico" en donde se apuesta por un mensaje de esperanza (Maldonado, 1997, p. 53), porque dentro de esta sociabilidad y antropología de la mesa, "toda comida y bebida suponía una comunidad íntima entre los participantes que provenía del hecho de ser el pueblo elegido" (Maldonado, 1997, p. 65).

Pero Jesús rebasa este marco conceptual, para lo cual Maldonado retoma el término de "comensalidad abierta", porque "[1]a praxis de Jesús en el comer y en el beber no se limita exclusivamente al círculo estrecho de los discípulos, sino que está abierta, tanto religiosa como socialmente" (1997, p. 65). La multiplicación del pan es su formulación más audaz; pero la más característica sería la de la última cena para aludir así al alimento en tanto don salvífico enviado por la divinidad. Así, este episodio tiene dos elementos desde punto escatológico que deben resaltarse: esta cena posee una connotación de sacrificio, mientras la comunidad se reúne 
para aceptar su connotación mesiánica. Su formulación ritualística en la consagración se adapta para subrayar la actualización de su valor experiencial, al servicio ahora del "vino del derecho", reivindicación de la justicia que debe reinar en esta nueva fraternidad humana convocada por el yo lírico, celebrante y profeta. Tal dinámica pone en vigencia la puesta en escena de una comunidad, la cual supone la noción de pertenencia y de inclusión. Así, el poema introduce, por medio de los paréntesis, que tienen un valor opositivo, aquello que se excluye y que se opone a este sentimiento de comunidad y de colectividad, nacidas bajo el alero de la mañana; veamos:

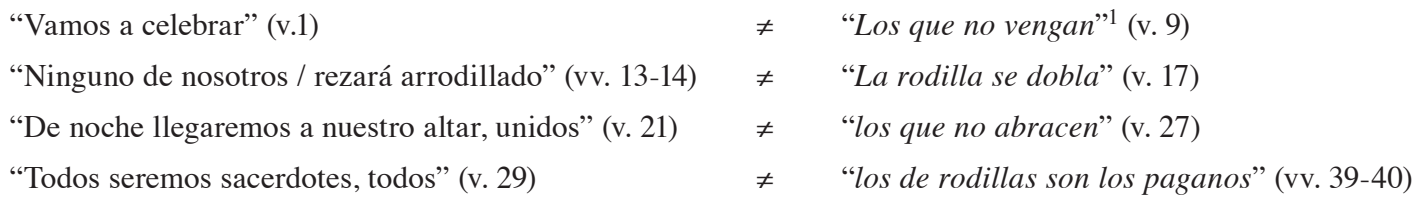

La estructura antitética del poema (entre las estrofas impares y las impares en cursiva, entre un "nosotros" y un "ellos", respectivamente) supone también una oposición entre dos concepciones de Iglesia: una tradicional y paseísta y otra renovada: se trata de esbozar la nueva liturgia de la eucaristía, para que prive la reunión comunitaria, de participación, de comunión en la idea de "abrazar" y en la que no hay jerarquías dentro de este sacerdocio universal y compartido. Debravo expone el nuevo credo en un poema exultante de júbilo y festivo desde la primera unidad que hemos analizado ya. Por eso, en tanto arropado por este nuevo espíritu, denuncia de esta manera a aquellos que rechacen esta convocatoria a la "misa del amor": "(Los que no vengan, / los enemigos, / rodarán solos / a malos ríos)” (Debravo, 1979, vv. 9-12, p. 17).

La condena es sin tapujos y revela el sentido directo de quien se abroga la función profética de la Buena Nueva; solo así podemos comprender el tono enfático y oracular de esta poesía que se sustenta en la receptividad del mensaje y, de este modo, interpreta la realidad a través de la dicotomía exclusión / inclusión y adjudicándose un registro pasional, en el sentido que demanda el cambio de actitud y la actuación según este sentimiento, para marcar diferencias en la configuración de la identidad colectiva:

\footnotetext{
Al añadir al reconocimiento de las diferencias la enunciación, al menos implícita, de juicios que conciernen al destino de los sujetos categorizados, superponen una verdadera dramatización de la desemejanza a lo que podría interpretarse, a primera vista, como una pura lógica de la distinción. (Landowski, 1993, pp. 106-107, [las cursivas son del texto]).
}

No nos extrañe, en este sentido, que domine una manipulación textual de los que no piensan como usted con el término de "enemigos", a los que separa y distingue en oposición radical desde el sistema comunicativo del poema: Ellos, "los enemigos", no son unas personas impersonales, son aquellos a los que pone cara e identifica el yo poético como seguidores de una religiosidad pasiva y trasnochada. Este "nosotros" inclusivo, en el que se escuda el "yo", representa también una colectividad en la medida en que forma parte de un todo y habla en nombre de ese grupo al cual pertenece, de donde encuentra su legitimidad y la fuerza de su discurso gracias a la "persona amplificada" (Prada, 1990, p. 37).

A la luz de lo anterior, la expresión popular "rodar cabezas" propio de quien le pasan la guillotina, anuncia el castigo divino de los que serán ahogados y tragados como "malos ríos", es decir, aquellos cuya mentalidad estancada y espíritu maloliente matan todo lo que cae sobre ellos. Esos "malos ríos" es como esas "aguas muertas" que Bachelard ve: "agua pesada, más profunda, más muerta, más adormecida que todas las otras aguas dormidas" 
(2003, p. 75, [las cursivas son del texto]). Se trata de un agua maloliente y que no fluye; por eso Debravo subraya la calidad de esos cuerpos anegados y ahogados en un agua putrefacta y sin dinamismo. Vayamos ahora a la siguiente unidad: "Ninguno de nosotros / rezará arrodillado: / rezaremos de pie, listos para la vida, / con los ojos volando. / (La rodilla se dobla / cuando las manos / están apabulladas / de fracaso)" (Debravo, 1979, vv. 13-20, p. 17).

La equivalencia con la estructuración de la unidad anterior permite no solo establecer la redundancia y la similitud que Debravo quiere mantener en la oposición dicotómica, sino también nos obliga a observar, con el paréntesis, un doble nivel poético, uno en oposición al otro, pues el paréntesis desemboca en la otra forma de Iglesia rechazada. Veamos, la actitud del creyente tradicional es la de rezar arrodillado, en el estado de prosternación, cuya praxémica -la cabeza cabizbaja, las manos cruzadas, el cuerpo en genuflexión- se rechaza en los versos 15 y 16: "rezará arrodillado", del verso 14, versus "rezaremos de pie" (v. 15) en una apertura radical que de nuevo la postura corporal revela: "listos para la vida" (v. 15). Así, no solamente funciona como una sinécdoque de brazos abiertos, sino también "los ojos volando", en cuanto una metonimia de la cabeza, señala esa disposición de mirar hacia la inmensidad de las alturas. Y lo es porque, como plantea Yadira Calvo (1980) en relación con estas actividades, prototípicas del cristiano, "'rezar' o 'arrodillarse' no son condenados sino por su ineficacia para salvar al hombre en esta vida y porque son en cierta manera dos símbolos de impotencia y sumisión" (p. 51).

Vistas así las cosas, la oposición alto / bajo se establece también como una actitud fresca de caracterizar al creyente que se renueva y despierta a un ritual liberador; en la posición del cuerpo se juega toda la batalla de entender una fe renovada y proclive al cambio, que Jorge Debravo coloca en la "mañana". Se trata de una contraposición sobre la actividad primordial del creyente (rezar), con su rechazo y cuestionamiento en los versos entre paréntesis: la "rodilla", doblada del verso 17, y "las manos" (v. 18), cerradas en la sinécdoque "apabulladas / de fracaso" (vv. 19 y 20), demarcan ese territorio de una oración solitaria y hueca. Todo ello supone una renovación que se justifica en cuanto disposición de festividad, para que la "misa buena" resplandezca en la alegría de la mañana, aquella que se canta desde los tiempos de los primeros cristianos y se condensa en un canto matinal que celebra la luz y la resurrección: "Alegre la mañana que nos habla de ti, alegre la mañana" alba como voluntad de renovación y de una nueva sensibilidad es capital para comprender su significación de un cambio dentro de una religiosidad más auténtica y sincera en Debravo.

La trascendencia y la oportunidad de cambio se imponen con la mañana y esa transición de la noche hacia el alba es lo que marca a Francisco Amighetti (1907-1998), cuando por medio de la ventana emprende la aventura de mirar hacia el horizonte, hacia la inmensidad de las alturas (ver el cielo y la inmensidad de las alturas) o hacia el espacio exterior (ver a los seres humanos y la naturaleza). Ver a través de la ventana adquiere la capacidad de iluminar su creación, de manera que la actividad demiúrgica de los "poetas" se intensifica a partir de esa retícula que es la ventana en tanto instrumento y procedimiento. Así, la sensación de profundidad reenvía de perspectiva en perspectiva al sujeto que contempla / se maravilla, se realiza a través de un horizonte en el que el mundo se propone como totalidad y apertura de "l’horizon" (Collot, 1989, p. 42). Así, el mundo y el cosmos se abren al poeta iluminado a través

$6 \quad$ Podrá el lector encontrar este canto en internet. 
y gracias a la ventana; la atracción de la mirada se dirige hacia sus posibilidades intrínsecas para contemplar / crear en un doble juego en el que el mundo se construye y se representa como espectáculo de belleza. Se vuelve, entonces, la ventana en metáfora perfecta del ojo creador, así como sinécdoque por antonomasia de la conciencia integradora. Es lo que sucede en el poema "Madrugada", de la sección "Retratos", en donde Amighetti despliega el tiempo ideal para que la revelación diferencial y radical se imponga y se ejercite la ensoñación creadora, en esa transición se explicita entre los versos 5 y 6 bajo el estímulo del alba: "Hay en mi casa unas ventanas, / cuando la noche pierde su luz negra, / y tiembla la madrugada con su plata lívida, empiezo a existir. / Todavía no llega la mañana / con su oro rosa" (Amighetti, 1974, vv. 1-6, p. 58).

En el inicio del poema Amighetti insiste en la deixis espacial con precisiones de carácter cromático-preciosistas ("cuando la noche pierde su luz negra / y tiembla la madrugada con su plata lívida" [vv. 2-3] o "no llega la mañana / con su oro rosa" [vv. 5-6]), para marcar el tiempo del crecimiento espiritual, el cual solamente es posible si dejamos esa realidad apariencial y se perfecciona la vida interior, restitutiva y reintegrativa por medio del movimiento interior de quien mira. Toda experiencia del horizonte conduce al observador poético hacia la percepción de la lejanía en tanto "aurora", pues, como planteara Gaston Bachelard, "el poeta aéreo conoce una especie de absoluto matutino, está llamado a la pureza aérea” (1997, p. 208, [las cursivas son del texto]):

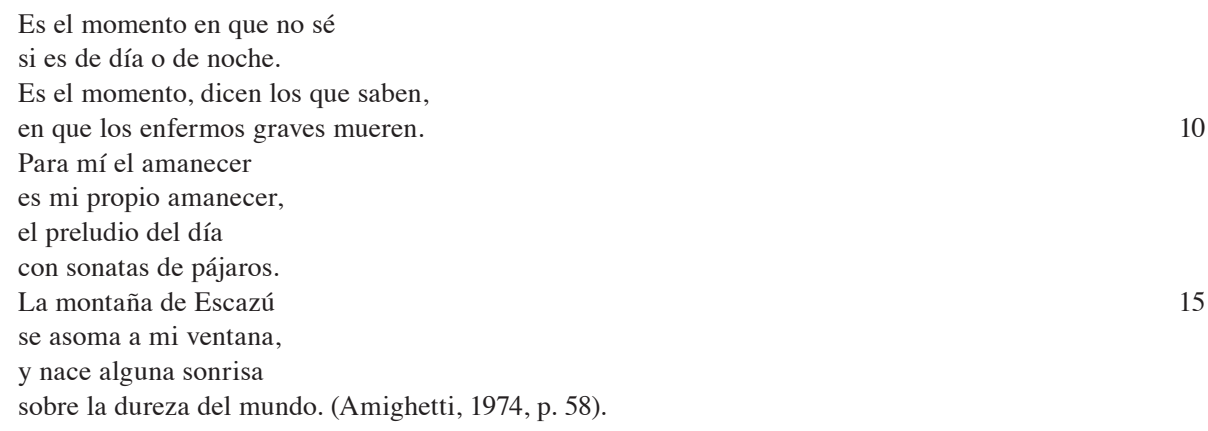

Retomando lo que la sabiduría popular acredita a la madrugada como un tiempo de intensificación en el que los corredores del Cielo se abren para llevarse a los moribundos, Amighetti pondera la "madrugada", pintada así en la primera parte del poema, desde la individuación subjetiva de quien no tiene temor ni se siente apabullado por la semi-oscuridad. Más bien, en cuanto transición, el cuadro-poema termina de pintarse cuando, del plano exterior, se pasa al desarrollo de la vida interior y al proceso de individuación. "Para mí el amanecer / es mi propio amanecer" (vv. 11-12), reivindica la voz poética, con lo cual se subraya no solo la receptividad de quien aguarda la luz del día, sino también su disposición personal a recibir lo que le repare al ser humano: la luz benéfica y bienhechora de la mañana. De esta manera, el poema traza, como si fuera una composición, los otros elementos que se despliegan en el cuadro-retrato personal, porque a través del paisaje el yo poético se presenta y transfigura. Vale la pena recordar que el poema se "enmarca", se coloca en esta sección del libro con el título de "Retratos". Así, "[1]a montaña de Escazú" y "mi ventana" funcionan no solo como puntos de referencia que marcan la deixis espacial, sino también la dirección de la mirada que, absorta y maravillada, bendice y recibe con algarabía las bondades del nuevo amanecer; la prueba de ello es esa "sonrisa" con la que se cierra el poema, para que la correlación entre mecanismos 
poéticos y el perfeccionamiento de la vida psíquica del artista / poeta sea evidente en la noche o también en las transiciones del día a la noche (el crepúsculo) o viceversa (la madrugada). De esta forma, se convierte en el tiempo ideal para llevar a cabo cualquier transformación del espíritu o de conciencia individualizada, tal y como observamos en el poema de Azofeifa.

El estado "subjetivo" de la madrugada transforma y lo es gracias a la ventana, abierta, receptiva y translúcida por la que deja entrar Amighetti la luz benefactora e irradia su trabajo y mirada de una manera exultante y pletórica. Laurent Jenny plantea con acierto que el encuadre de la ventana no es un mero decorado en la poesía francesa de finales del siglo XIX y, citando los casos de Mallarmé y Apollinaire, expone que "[e]s también una forma organizadora, es la figuración llena de imágenes de una división entre «interior» y «exterior»” (2003, pp. 99-100). Por lo tanto, el motivo de la ventana problematiza las posibilidades de la individualización subjetiva que realiza el poeta dentro de la oposición exterioridad / interioridad. Se trata de captar el lugar auténtico en el que se desarrolla la conciencia creadora, es decir, la ventana por la cual la conciencia se abre al mundo, "en cuanto a lo que persigue por la ventana, se trata de un espectáculo que, de entrada, está transfigurado imaginariamente [...], de suerte que [...] ve por la ventana sólo la imagen de su propio deseo" (Jenny, 2003, p. 101). Ese deseo y esa voluntad de transfiguración que la madrugada provoca en Amighetti, de tal suerte que al alba de la existencia, surge el impulso inquietante de la integración y restitución con el cosmos: ello provoca la transfiguración eufórica del yo poético, tal y como sucede en el poema "En el alba", de mi segundo poemario, Conjuros del alba (2014b). Precisamente toda la primera sección de este poemario se inscribe bajo el siguiente título: "Al alba de todas las cosas, la palabra”, con el fin de apelar a esa verdad que San Juan catapultaba al inicio de su evangelio, al privilegiar esa relación entre la palabra y la creación, de preeminencia órfica.

De esta manera, la asociación entre el conjuro mágico y la poesía adquieren toda su dimensión metapoética en un poemario que diseña esa preocupación por develar los secretos y conjuros, de los sortilegios de la palabra poética, transida siempre por el ritual y por el deseo de quien ejerce el oficio. El poema que voy a comentar, "En el alba", está dividido en dos partes por signos ortográficos que intentan reproducir el silencio y la reflexión insondable que la madrugada precipita en quien cavila y retoma sus fuerzas, tal y como se produce también en el poema de Amighetti:

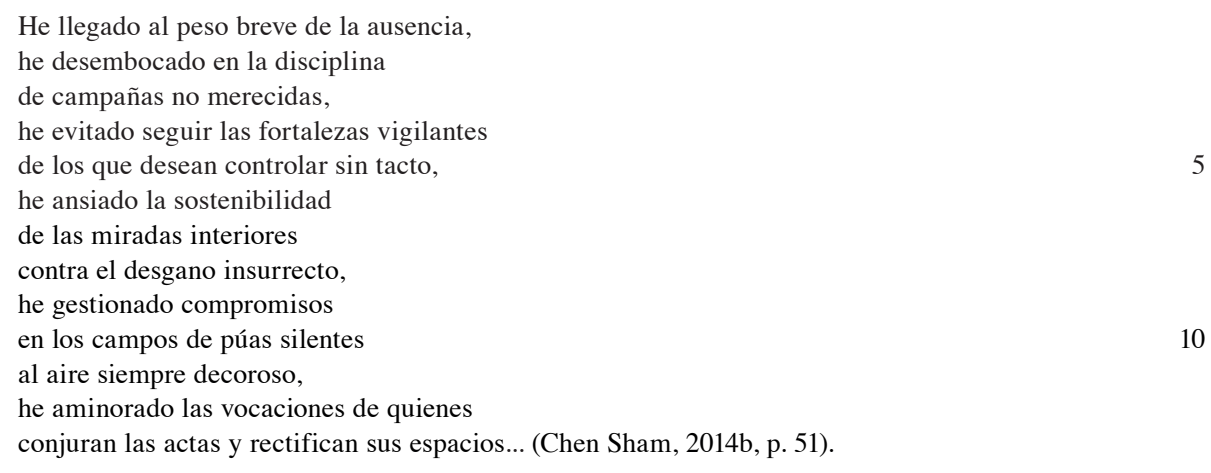

La transición de la noche a la mañana se esboza con la imagen de "al peso breve de la ausencia" del verso 1, en donde se motivan por el aire y la ligereza. Toda la simetría temporal de la primera estrofa se produce gracias a la utilización del pretérito compuesto; 
su primera realización marca el punto de llegada dentro de lo que se desarrolla en el poema como un camino de aprendizaje, entre las barreras y obstáculos que se han intentado superar ("he desembocado", "he evitado" y "he aminorado") y la manera de enfrentarlos y combatirlos ("he llegado", "he ansiado" y "he gestionado"). El poema se plantea, entonces, como una recapitulación biográfica que el alba provoca e intensifica en tanto iluminación y balance y ello es posible porque, en esta primera estrofa, todo aquello a lo que se ha enfrentado el yo poético, "la disciplina / de campañas no merecidas" (vv. 2-3), "las fortalezas vigilantes / de los que desean controlar sin tacto" (vv. 4-5) o "las vocaciones de quienes / conjuran las actas y rectifican sus espacios" (vv. 13-14) representan los peligros y quienes se manifiestan como sus enemigos. Ante un balance así concebido con escollos y obstáculos, debe surgir una estratagema para capear los embates y no caer en la desgracia de fracasar o "morir en el intento", lo cual se expone como convencimiento y entereza entre los versos 6 y 11: "he ansiado la sostenibilidad / de las miradas interiores / contra el desgano insurrecto, / he gestionado compromisos / en los campos de púas silentes / al aire siempre decoroso". Dos imágenes se imponen aquí, "el desgano insurrecto" y "los campos de púas silentes" que subrayan esa exposición del yo poético ante la existencia vista como desafío y enfrentamiento, para que ese punto de llegada se presente en la segunda estrofa de esta primera parte del poema en términos de un aprendizaje aún no terminado. El juego verbal entre el pretérito compuesto y el presente involucra esa conciencia de un proceso en marcha y todavía no conclusivo:

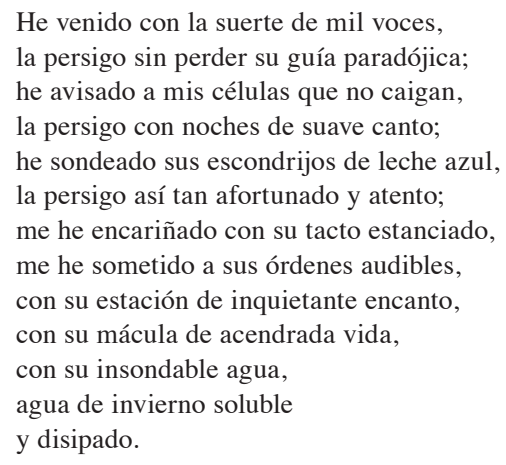

(Chen Sham, 2014b, p. 51, [los puntos suspensivos son texto]).

De esta manera, el balance recapitulativo nunca implica aquí ni un cierre ni una valoración última, para que la intertextualidad surja e ilumine al lector en este balance propuesto. La forma verbal "la persigo" insiste en la acción continua y esforzada de quien aborda esta experiencia de forma más o menos consciente, con ese vacío semántico de que no existe un referente explícito para el pronombre "la" en el poema. La intertextualidad, en cuanto evocación de una cita o de una relación textual debe activarse para llenar este vacío, pues es indudable ${ }^{7}$ que remite al poema conclusivo de Prosas profanas, "Yo persigo una forma..." (Sección "Las ánforas de Epicuro", que Rubén Darío agrega a la segunda edición, París, 1901); veamos el cuarteto inicial: "Yo persigo una forma que no encuentra mi estilo, / botón

7 Cosa que no tenía claro cuando escribí el poema; pero que ahora se vuelve una iluminación personal de textos y lecturas que trabajan y se posicionan, consciente o no conscientemente, en el archivo de la memoria. 
de pensamiento que busca ser la rosa; / se anuncia con un beso que en mis labios / se posa al abrazo imposible de la Venus de Milo" (Darío, 2008, p. 426).

Lo que Rubén Darío plantea, al colocar este poema al final de Prosas profanas, es su vocación y camino de aprendizaje. En su proceso de búsqueda, atento siempre a unas expresiones de belleza, Darío encuentra que las certidumbres son pocas, cuando el oficio lo obliga a enfrentarse a "una forma" que siempre se le escapa (la paradoja de la iluminación poética), pues la experiencia estética no puede definirse ni atraparse de forma transitiva. La Poesía se escapa al trabajo consciente de un "estilo" deliberado y se plantea como una búsqueda siempre en perpetuo cambio y movimiento de lo indecible, que más bien de rebote le devuelve al poeta más preguntas que verdades y se manifiesta como un deseo siempre por colmar $^{8}$. En esta segunda estrofa del poema "En el alba", tres veces se increpa y se conjura mágicamente a la Poesía: "la persigo sin perder su guía paradójica" (v. 15), "la persigo con noches de suave canto" (v. 17) y "la persigo así tan afortunado y atento" (v. 19); el proceso de la creación se explicita en esa duración de la noche de todos los encantos y de todos los deseos, para quien se transfigura con su llamado / posesión siempre inquietante y acuoso, insondable y fluido, por su relación con el flujo de las aguas, tal y como se explicita entre los versos 24 al 26. De esta manera, los puntos suspensivos al final de esta primera estrofa apuntan a esa transformación interior que deja, a quien apela a la Poesía, en un estado de apabullamiento o de silencio. Todo ello desemboca en la estrofa final del poema, la cual comprende la segunda parte del poema, en donde se pasa en esa transición temporal de la noche al alba. Del verso 1, "He llegado al peso breve de la ausencia" al verso "he vuelto de ese camino al peso breve" (v. 28) no se cierra ningún ciclo; más bien se apuesta por la transición renovadora bajo esa luz que todo lo resplandece, para que la acción de "volver" sea el punto de arranque y de inflexión y la palabra inunde el cosmos, la naturaleza exuda y canta al júbilo y al compás de la "palabra" (v. 30), con lo cual se apela a la fuerza del himno a la naturaleza en el modelo franciscano.

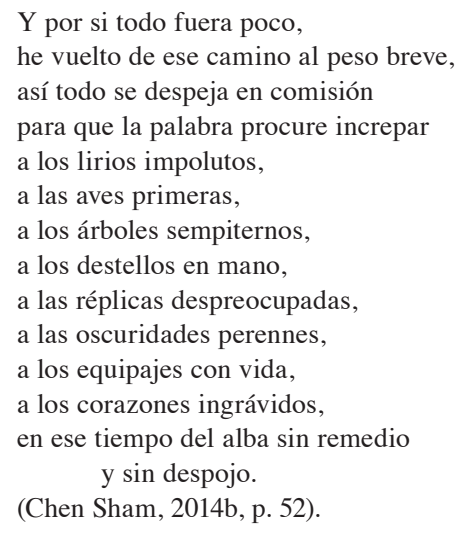

$8 \quad$ Véanse los dos tercetos del poema de Darío:

Y no hallo sino la palabra que huye,

la iniciación melódica que de la flauta fluye

y la barca del sueño que en el espacio boga;

y bajo la ventana de mi Bella-Durmiente,

el sollozo continuo del chorro de la fuente

y el cuello del gran cisne blanco que me interroga. (Darío, 2008, p. 426). 
Y como en las versiones de Amighetti y de Debravo, todo se transfigura para que las acciones y los avatares humanos se aligeren y se pongan en balance; entonces se justifica poner todo en su justa dimensión para que el "peso" de la existencia no sea tan oneroso ni problemático, cuando todo se renueva y se clarifica en el "alba" de la renovación a la que nos invita este recorrido por la notación temporal de la "mañana". En este recorrido por poetas costarricenses (entre los cuales me incluyo yo), la palabra poética se convoca al son de la luz matinal; es júbilo, acción, algarabía, reflexión, apertura y esperanza renovadora, de modo que explica un decurso que cobra sentido, según consideraba Azofeifa en su auto-explicación, "consciente de su existencia" (1975, p. 13) y "a partir de [su] personal experiencia" (1975, p. 19). Todo ello desemboca no solo en la reflexión metapoética de una escritura que siempre inquieta, sino también en la del poema que tanto perturba y se reconfigura, porque, como indica Azofeifa, "la búsqueda de la expresión sigue siendo el trabajo nunca terminado de los poetas" (1975, p. 22). Siempre atento al poder del lenguaje y del ritual que lo acompaña (el poético), su concepción se moldea bajo el oficio del "encantador, un prestidigitador que usa sus palabras para tejer su propio universo", propone Mayela Vallejos Ramírez en su introducción a Conjuros del alba (2014, p. 4); su irradiación benéfica, protectora, catártica se produce bajo la luz matinal, cuya función catártica incentiva el papel simbólico y material, de la claridad que todo lo transfigura y redinamiza, pues la dinámica del fuego, y por lo tanto también de la luz, está signada por el "experimento" (Calatrava, 1997, p. 149) maravilloso y técnico que se abre a los ojos humanos y promulga tanto la renovación como el impulso constructivo.

\section{Bibliografía}

Abrams, M. H. (1992). El Romanticismo: Tradición y revolución. Madrid: Editorial Visor.

Amighetti, F. (1974). Poesías. San José: Editorial Costa Rica.

Azofeifa, I. F. (1974). Vigilia en pie de muerte. San José: Editorial Costa Rica.

Azofeifa, I. F. (1975). Mundo, vida y poesía o autolectura para explicarme. Revista de Filología y Lingüística de la Universidad de Costa Rica, 1(2), 3-28.

Bachelard, G. (1997). El aire y los sueños: Ensayo sobre la imaginación del movimiento. México, D. F.: Fondo de Cultura Económica.

Bachelard, G. (2003). El agua y los sueños: Ensayo sobre la imaginación de la materia. México, D. F.: Fondo de Cultura Económico.

Barthes, R. (1966). Crítica y verdad. México, D. F.: Siglo Veintiuno Editores.

Béguin, A. (1993). El alma romántica y el sueño: Ensayo sobre el romanticismo alemán y la poesía francesa. Madrid: Fondo de Cultura Económica.

Bousoño, C. (1976). Teoría de la expresión poética. Madrid: Editorial Gredos.

Calatrava, J. A. (1997). Del incendio primigenio al resplandor del sublime: visiones del fuego en la cultura estética de las luces. En J. A. González Alcantud y M. J. Buxó Rey (Eds.), El fuego: mitos, ritos, realidades (pp. 147-166). Barcelona: Editorial Anthropos / Diputación Provincial de Granada.

Calvo, Y. (1980). Poesía en Jorge Debravo. San José: Ministerio de Cultura, Juventud y Deportes. 
Collot, M. (1989). La poésie moderne et la structure d'horizon. París: Presses Universitaires de France.

Chen Sham, J. (2007). La expresión hímnica en el Psalterio: el caso de Ernesto Cardenal. Revista de Filología y Lingüística de la Universidad de Costa Rica, 33(1), 21-32.

Chen Sham, J. (2014a). La 'ventana' de todos los asombros en la poesía de Francisco Amighetti. Revista de la Academia Norteamericana de la Lengua Española, 3(6), 343-353.

Chen Sham, J. (2014b). Conjuros del alba. San José: Editorial Universidad de Costa Rica.

Darío, R. (2008). Azul... / Prosas profanas / Cantos de vida y esperanza. León: Editorial Universitaria UNAN-León / Universidad de Alcalá de Henares.

Debravo, J. (1979). Nosotros los hombres. (2 ed.). San José: Editorial Costa Rica.

Fernández Leborans, M. J. (1977). Campo semántico y connotación. Madrid: CUPSA.

Gelabert, M. (1990). Valoración cristiana de la experiencia. Salamanca: Editorial Sígueme.

Jenny, L. (2003). El fin de la interioridad: Teoría de la expresión e invención estética en las vanguardias francesas (1885-1935). Valencia: Ediciones Cátedra / Frónesis.

Kayser, W. (1981). Interpretación y análisis de la obra literaria. Madrid: Editorial Gredos.

Landowski, E. (1993). Ellos y nosotros: notas para una aproximación semiótica a algunas figuras de la alteridad social. Revista de Occidente, (140), 98-118.

Lona, H. (2003). Las cartas apostólicas. Buenos Aires: Editorial Claretiana.

Maldonado, L. (1997). Eucaristía en devenir. Santander: Editorial Sal Terrae.

Mannati, M. (1979). Orar con los salmos. (2 ed.). Estella, Navarra: Editorial Verbo Divino.

Monge, C. F. (1984). La imagen separada: modelos ideológicos de la poesía costarricense, 1950-1980. San José: Instituto del Libro.

Paz Gago, J. M. (1999). La recepción del poema: pragmática del texto poético. Kassel: Universidad de Oviedo / Edition Reichenberger.

Pozzi, G. (1976). Releyendo el Cántico del hermano sol. Recuperado de http://www. franciscanos.org/estudios/pozzi.htm

Prada Oropeza, R. (1990). Constitución y configuración del sujeto en el discurso-testimonio. Casa de las Américas, 30(180), 29-44.

Rojas M. y Ovares, F. (1995). 100 años de literatura costarricense. San José: Editorial Farben / Norma.

Santa Biblia. (1974). Madrid: Ediciones Paulinas.

Vallejos Ramírez, M. (2014). El ensalmo y otros rituales mágicos en Conjuros del alba (Estudio introductorio). En J. Chen Sham, Conjuros del alba (pp. 1-12). San José: Editorial de la Universidad de Costa Rica. 